\title{
Studying in the United States: Language Learning Challenges, Strategies, and Support Services
}

\section{Debra M Wolf ${ }^{\mathrm{a}}$ and Linh Phung ${ }^{\mathrm{a}}$}

\begin{abstract}
A case study was conducted to explore the experiences of Chinese nurses when completing a graduate nursing degree taught in English (as a second language) in the United States over a 1-year period. The study explored language, academic, and social challenges perceived by the students, strategies used to overcome challenges, and academic support services designed to help students succeed in their studies. Survey data were collected at three different points in time, and three interviews were conducted with each participant. The study identified participants' difficulty with academic writing, mixed experiences with speaking, moderate-to-high levels of strategy use, and appreciation of the support services offered. The study offered implications for improvements in pedagogies and programming for international students.
\end{abstract}

Keywords: language learning, study abroad, language challenges

\section{Introduction}

Higher education today is changing with increased opportunities for students to travel to other countries to obtain higher degrees. In the United States alone, the number of international students in 2016-2017 reached the all-time high of nearly 1.1 million, 32.5\% of whom were Chinese students (Institute of International Education, 2017). International students in the US are defined as those who need immigration documents from a U.S. institution in order to apply for a visa to enter the country. Studying abroad exposes students to global experiences that fulfill learning objectives and opportunities that differ from what they have access to in their country. In the United States and Australia, one particular type of program growing yearly is bachelor's and master's degrees in nursing for Chinese students. With the increase of international students from China, there are challenges academic institutions must be prepared to address. Wang, Andre, and Greenwood (2015) completed a literature review that identified a range of challenges for Chinese international students (including nursing students). Key challenges focused

\footnotetext{
${ }^{a}$ Chatham University.
} 
on English language proficiency, different learning styles, and cultural differences. The authors called for further research into lived experiences of Chinese nursing students studying abroad.

To address this need for further research, a case study was conducted to explore language-related experiences of Chinese bachelor's-prepared nurses studying in the United States over a 1-year period. More specifically, the study aimed to identify the language challenges experienced by the nurses, strategies used to overcome the challenges, and the usefulness of English as second language (ESL) and academic support services provided. The study collected both quantitative and qualitative data to triangulate the findings and gain a deeper understanding of the participants' experiences. The findings from the study offered implications for improvements in pedagogies and programming for international students.

\section{Literature Review}

International students studying in a second language (L2) and in a new environment have been found to face numerous challenges, including linguistic, academic, and sociocultural challenges (Gu, 2011; Huang, 2012; Kuo, 2011; Lee, 2010; Leong, 2015; Li, Wang, Liu, Xu, \& Cui, 2018; Parris-Kidd \& Barnett, 2011; Wang, Andre, \& Greenwood, 2015). Rosenthal, Russell, and Thomson (2008) found that, among 979 international students surveyed, $24 \%$ of Asian students reported having difficulties in written English and $22 \%$ in spoken English as well as a high level of stress. Li et al. (2018) reported frequent references to challenges related to English proficiency, connections with locals, course readiness, and time management among 13 East Asian international students studying in the US. A study by Kuo (2011) explored language challenges faced by international graduate students in the United States. Among the 716 students invited to complete an online survey, 152 responded. The authors identified that standardized test scores did not accurately predict academic success nor alert faculty of language challenges of studying abroad. The two main challenges reported were listening comprehension and oral communication outside the classroom. Participants in the study also reported difficulties with terminologies in their reading materials. The author attributed the difficulties to the lack of development of language skills needed to study at an American institution. In a qualitative study with 11 international students, seven of whom were Chinese, Leong (2015) also found English language proficiency as the primary barrier to students' academic success.

A recent study by Mitchell, Del Fabbro, and Shaw (2017) explored language learning needs of Chinese international nursing students and identified that students felt isolated, studying took longer, stress impacted their ability to communicate, and they needed to develop their proficiency in speaking English. The authors presented two major themes from their study: Chinese nursing students had difficulty expressing themselves and "finding their place" (a sense of belonging) when studying abroad. The latter theme is similar to what Horne, Lin, Anson, and Jacobson (2018) reported in their study comparing international undergraduate and U.S. undergraduate students. While there have been many studies investigating international students' numerous challenges, Wang et al. (2015) acknowledged a need for "further research into the lived learning experience of Chinese nursing students" studying abroad (p. 609). The present study examined the 
experiences of this particular population in the US with a focus on language-related challenges.

Although challenges have been found to be common, strategy use has also been identified as important for academic success. The L2 learning literature in particular has emphasized the importance of learners' active and creative participation in the learning process through individualized language learning strategies (Dornyei, 2010; Ozgur \& Griffiths, 2013). Oxford (1990) defined language learning strategies as "specific actions taken by the learner to make learning easier, faster, more enjoyable, more self-directed, more effective, and more transferable to new situations" (p. 8). Frequent strategy use indicates a high level of self-regulation and effort, which plays an important role in L2 learning success (Dornyei, 2010; Ozgur \& Griffiths, 2013). Language learning strategies have been categorized in various ways. One of the most popular taxonomies is Oxford's (1990) Strategy Inventory for Language Learning (SILL). This taxonomy places different strategies into six categories: memory, cognitive, compensation, metacognitive, affective, and social. The taxonomy has been used extensively to investigate the relationship of strategy use and a language learner's degree of success.

Green and Oxford (1995) used the SILL to study language learning strategies used by language learners in Puerto Rico and found greater use of strategies among more successful learners. The learners' strategy use was also qualitatively different from less successful learners'. Griffiths (2003) used the SILL to investigate the relationship between strategy use and course level in a private language school in New Zealand. The author discovered that higher level students frequently used more language learning strategies. In a recent literature review, Griffiths and Oxford (2014) concluded that while the relationship between strategy use and proficiency is complicated, there is a significant positive correlation between strategy use and successful language learning. However, strategy use among students who attend a degree taught in English in another country has not been explored.

This case study addresses the gaps in research mentioned above by exploring the challenges that a cohort of Chinese nursing students faced while studying abroad in their L2, the strategies they used to overcome the challenges, and the usefulness of the support services provided to them. The study collected data at three different points in time during the participants' program of study. In addition, the study is unique in that the students who participated in the study arrived in the US as a cohort group versus individual international students integrated into an existing program with domestic students.

\section{Methods}

\section{Participants}

Participants were eight bachelor's-prepared Chinese nurses enrolled in a three-term onground Master's of Science in Nursing Education program in a small private mid-Atlantic university. There were two male and six female participants, who had several years' experience working as a nurse in different specialty areas in their home country. At the time of admission into the program, their International English Language Testing Scores (IELTS) ranged from 5.5 to 7.0, indicating a proficiency level between intermediate to low- 
advanced. The students studied as a cohort in an on-ground program, for the traditional master's program in nursing at the university was fully online for students from the US.

\section{Data}

The study collected both quantitative and qualitative data over a period of one year. Participants completed one electronic survey and participated in an interview at the end of each term (fall, spring, and summer). The two sources of data were used to triangulate the findings to answer the research questions. The study was descriptive and exploratory in nature with the aim to generate greater insights into a particular cohort of students.

\section{Materials}

Materials used to collect the data in the study included one electronic survey and an interview using a predefined script. The survey was a combination of two surveys. The first one was a 22 item self-developed survey focused on exploring challenges and academic and support services available to participants. Participants responded to each statement by selecting a number from 1 (not challenging or not helpful) to 5 (extremely challenging or extremely helpful). The second survey was the SILL with 55 items and six subcategories, each of which had six to 14 individual statements (Oxford, 1990). Participants were to respond to each statement by selecting 1 (never true of me) to 5 (always true of me). The SILL survey has a reliability factor (Cronbach alpha) of .93-.98 (Oxford \& Burry, 1993; Oxford \& Burry-Stock, 1995). For each interview, an interview script was used to ensure consistency, but follow-up questions were also asked. Table 1 shows the pre-determined interview questions.

Table 1. Interview questions.

Please state the code number you were assigned.

What has been your experience so far with studying in English?

What class activities are easy for you? What are difficult for you? Why?

What skill (reading, writing, listening, or speaking) do you find easy? What do you find difficult? Why?

Do you find the readings in your graduate courses easy or difficult? Why?

Do you find the writing assignments easy or difficult? Why?

Do you find giving a presentation easy or difficult? Why?

How about using language outside the classroom? What do you use English/Chinese? What are the challenges?

What are your strategies to overcome the challenges?

\section{Procedure}

The study was approved by the Institutional Review Board of the university. During the first week of the program, the Dean of the School of Health Sciences sent an email to encourage 
the students to participate in the study. All of the students $(n=8)$ signed a consent form to volunteer as participants. After consenting, each participant picked a code from 1 to 8 to be used when submitting surveys and during the interviews. The interviewer asked nine predetermined questions (Table 1) and used follow-up questions to clarify meaning or to encourage participants for further elaboration of their thoughts. The interviews were audio recorded and transcribed for data analysis.

\section{Analysis}

The quantitative data from the survey were entered into Microsoft Excel 2010 for analysis. Due to one participant only responding to the survey at the end of the fall and spring terms (using the same score for all items on the SILL), this participant's data were removed. A mean score for each category in the SILL was calculated for each participant as well as for all seven participants to determine whether participants demonstrated low use (means around 1.0-2.0), medium use (means around 3.0), or high use of strategies (means around 4.0-5.0). With items related to the challenges of various academic tasks and the perceived usefulness of support services, mean scores of seven participants were calculated for the fall, spring, and summer. These means were examined together with the qualitative data to better understand the participants' experiences as related to the demands of studying a degree in English as a second language abroad.

The interviews were transcribed by a professional transcriber and reviewed by a research assistant. The transcripts were then entered into NVivo 11 for data analysis. During data analysis, the following parent codes were assigned to the participants' content: difficulty $(+,-$, or mixed); language skills and knowledge (speaking, writing, writing, vocabulary, and grammar); sources of difficulty; sources of ease; and strategies. The child codes under sources of difficulty, sources of ease, and strategies emerged from the data, which meant the researcher did not have predetermined codes for them. The second researcher conducted the coding herself, but went through all the codes with the first researcher to resolve any differences in opinions. The results section will report the findings from the quantitative analysis and the themes that emerged from the qualitative analysis to answer the research questions regarding the challenges that the participants faced, the strategies that they used to overcome the challenges, and the helpfulness of various support services and programs at the university.

\section{The Researchers}

The first researcher of the study was the Coordinator of the International Nursing Program where the participants enrolled within the U.S. university. She oversaw the admission and advancement of the participants throughout the program as well as the curriculum and instruction. The second researcher was the Director of the English Language Program, which offered support services to the participants. Both researchers worked closely with the students throughout the 12-month period, and their knowledge of the participants, the curriculum and services offered, and the university context contributed to the interpretation of the data. To ensure the credibility and trustworthiness of the study, 
the two researchers consistently cross-checked data coding and analysis, and discussed the findings.

\section{Results}

A total of eight Chinese nursing students were invited to participate in the study. The size was limited because the total number of students accepted into the fall cohort that year was eight. A response rate of $100 \%$ was obtained, with all eight agreeing to participate. The findings are reported according to the questions investigated in the study and the major themes that emerged from both the quantitative and qualitative data.

\section{Challenges}

Table 2 displays the "challenge" mean scores that participants gave to various academic tasks and some other aspects of their experiences when studying abroad.

Table 2. Perceived Challenges $(\mathrm{N}=7)$

\begin{tabular}{llll}
\hline \multicolumn{1}{c}{ Statement } & Fall & Spring & Summer \\
\hline & & & \\
Reading materials from graduate courses & 2.85 & 2.00 & 1.83 \\
Understanding lectures & 3.00 & 2.14 & 2.33 \\
Taking notes & 2.14 & 2.00 & 2.17 \\
Participating in classroom discussion & 2.71 & 1.86 & 2.33 \\
Working in groups with other students & 1.71 & 1.86 & 2.33 \\
Giving a presentation & 2.43 & 1.86 & 2.33 \\
Writing research papers & 3.86 & 2.57 & 3.17 \\
Writing short papers & 2.86 & 2.00 & 2.33 \\
Finding sources for my papers & 2.14 & 1.86 & 2.17 \\
Communicating with professors outside the & 2.86 & 1.86 & 2.00 \\
classroom & & & \\
Managing my time & 3.00 & 2.00 & 2.33 \\
Managing my emotions & 2.43 & 2.14 & 2.00 \\
Making friends & 2.86 & 1.86 & 2.16 \\
\hline
\end{tabular}

Note. Scale: 1 (not at all challenging), 2 (a little challenging), 3 (challenging), 4 (very challenging), or 5 (extremely challenging).

As noted in Table 2, in the fall term (the participants' first semester studying abroad), participants found many of the tasks challenging with the means for those tasks approaching 3.00. Especially, they rated writing research papers as very challenging $(M=$ 3.86). In the spring semester, participants rated all of the tasks as only a little challenging, indicating their increased confidence with the tasks. In the summer term, all of the tasks remained "little challenging" except for writing research papers, which was still rated as challenging at the conclusion of the program $(M=3.17)$. 
Qualitative findings confirmed that writing was challenging for the participants as the majority of the references to writing in the interviews were associated with difficulty. Participants attributed difficulty to their unfamiliarity with academic writing, especially the American Psychological Association format, and the rubrics or "what the professor needed" with each assignment. They also acknowledged the demands of writing in a second language in the academic style in terms of (1) voice (e.g., the restriction on the use of I, my, and we); (2) organization; (3) accuracy, logic, and clarity of sentences; and (4) mechanics. Despite the progress they made in writing after three semesters, some participants felt they still made mistakes that were "deep in [their] heart" and still conducted their "language thinking" in their mother tongue. One participant described the experience with writing assignments in the last interview as:

I think they are still difficult for me because some language thinking is different. I can make it grammatically right, but I can't write it like an American, like a native, because the native doesn't writing things like we do. I just can make it less error, that I can do, but I cannot make it like perfect.

Based on the qualitative analysis of the interviews, another language area that participants largely rated as difficult was listening, both in and outside the classroom. Participants said they had difficulty understanding native speakers, professors in class, and webinars or TED talks because of speed, difficult vocabulary, different accents, and a different "logical system." Participants mentioned one reason for the difficulty in listening was that they mostly listened to textbook recordings and had little opportunity to listen to native speakers while learning English in China. The lack of understanding or improvement in listening abilities sometimes resulted in the feeling of embarrassment and frustration.

Perceptions of speaking were quite mixed, partly because participants described their experience with speaking in various situations and academic tasks, including classroom discussions, academic presentations, conversations with native speakers, and interacting with preceptors during their clinical experience. Regarding giving a presentation, some participants found it difficult because of little prior experience, anxiety, and the demand of the task itself (i.e., having to memorize and present difficult content to an audience with words that were difficult to pronounce). However, some found giving a presentation not very difficult because they had experience giving presentations as nurse trainers. Participants mentioned having several opportunities to practice presentations as part of their course requirements within the Master's of Science in Nursing program. In addition, some participants really enjoyed sharing their opinions, expertise, and even emotions to their classmates and professors, especially when the topics were "in their zone." One participant described finishing a presentation as completing a great mission as they could make others "understand" and "admire" their accomplishments. Apparently, there were various emotions associated with giving a presentation, including anxiety, satisfaction, and pride. In addition to presentations, conversations with preceptors were all viewed positively since they gave them opportunities to "chat" and use English professionally. However, "daily communication" was described as mostly difficult because of, according to the participants, the lack of understanding on their part, the difficulty 
in expressing meaning, and cultural differences. These difficulties resulted in a range of negative emotions, such as stress, embarrassment, shame, loss of confidence, and even "suffering." One participant recounted an incident with the local Social Security office when lack of understanding caused the individual and the classmates to feel ashamed and embarrassed:

I remember last time we went to apply our social secure security, the police in the SSN office, when we entered the office he speak a long sentence in English that we just can understand I, you (laugh) in a sentence. But he is police and he had a gun and we were too ashamed to ask to say it again. And we look at each other very embarrassed and it looks like we are not doing something good (laugh).

Different from writing, listening, and speaking, reading was perceived as not so difficult because participants had more exposure to reading in China and they could use a dictionary to look up new words. In addition, they felt reading became easier at the end of the program because of the amount of academic and technical vocabularies acquired after three semesters of academic course work.

In general, both quantitative and qualitative data suggest specific challenges that a group of Chinese nurses face studying for an advanced degree in the United States in English. The qualitative data offer insights into their struggles with writing, listening, and speaking and the emotions associated with them. The Discussion section will connect these findings with current literature on experiences of international students in the US.

\section{Strategies}

Mean scores reflecting strategy use were analyzed based on the six subsections of the SILL (Table 3).

Table 3. Overall mean of Strategy Inventory for Language Learning subsections $(\mathrm{N}=7)$.

\begin{tabular}{llccc}
\hline \multicolumn{1}{c}{ Strategy } & Fall & Spring & Summer & Overall mean \\
\hline Memory strategies & 2.94 & 3.73 & 3.39 & 3.33 \\
Cognitive strategies & 3.39 & 3.83 & 3.50 & 3.58 \\
Compensatory strategies & 3.60 & 3.86 & 3.55 & 3.68 \\
Metacognitive strategies & 3.33 & 3.81 & 3.71 & 3.59 \\
Affective strategies & 3.29 & 3.95 & 3.45 & 3.57 \\
Social strategies & 3.48 & 3.69 & 4.14 & 3.70 \\
\hline
\end{tabular}

Note. Scale: 1 (Never true of me), 2 (Usually not true of me), 3 (Somewhat true of me), 4 (Usually true of me), 5 (Always true of me).

The data demonstrate that participants used language learning strategies at moderate to high levels with the means for all subsections of the SILL ranging from 2.99 to 4.14. Interestingly, they reported a higher level of strategy use in the spring semester with most of the means approximating 4.0. Noticeably, participants reported the highest level of use in the category of social strategies in the last semester $(M=4.14)$. 
The qualitative data illustrate some interesting themes around language learning strategy use. When asked what strategies participants used to overcome the challenges, several mentioned a wide variety of strategies, the majority of which were coded "learning strategies" as participants mentioned their efforts to listen more, read more, practice more, use dictionaries, and find more opportunities to talk with native speakers to learn from them. Considering the difficulty that participants reported when interacting with native speakers, it was encouraging that they reported using compensatory strategies, such as asking others to slow down, asking for repetition, checking understanding, guessing, and paraphrasing. While these strategies certainly helped, having to use them also indicated to the participants that they were struggling and did not always result in communicative success. Consistent with a result from the quantitative analysis, participants reported repeated use of social strategies, including asking peers, tutors, and professors for support. What was interesting was that participants consistently reported consulting other fellow students in their cohort when they did not understand an assignment or when they made mistakes or had difficulty communicating with others outside the classroom. Peer support seemed quite strong. Also encouraging was their use of tutors at the university for further support. Participants also highly appreciated the kindness from professors, who slowed down, encouraged them, and helped them in their study.

\section{Usefulness of Academic and Support Services}

Table 5 shows the means of the "helpfulness" scores that participants gave to academic and support services offered to them during the study period. The description of the services is included in Table 4 below.

Table 4. Description of services.

\begin{tabular}{ll}
\hline ELP workshops & $\begin{array}{l}14 \text { three-hour workshops on academic writing and } \\
\text { speaking } \\
\text { Weekly tutoring to assist with writing assignments }\end{array}$ \\
ELP tutoring & $\begin{array}{l}\text { Optional program offered through ELP to partner stu- } \\
\text { dents with English speaking individuals for a 1:1 conver- } \\
\text { sation in the fall and spring terms }\end{array}$ \\
Free 1:1 service offered by PACE to assist students with \\
Tutoring from PACE & $\begin{array}{l}\text { any academic learning and writing needs } \\
\text { froup workshops offered to all students through the year, }\end{array}$ \\
Workshops from PACE & $\begin{array}{l}\text { Workshops offered through the Office of Student Health } \\
\text { to help students with cultural adjustments } \\
\text { Workshops from Health Services }\end{array}$ \\
Advising, guidance, and direction as needed from \\
assigned faculty from each course as well as an academic \\
advisor.
\end{tabular}

Note ELP = English Language Program; PACE = Programs for Academic Access, Confidence, and Excellence. 
Table 5. Helpfulness scores $(\mathrm{N}=7)$.

\begin{tabular}{lcccc}
\hline \multicolumn{1}{c}{ Service } & Fall & Spring & Summer & Overall mean \\
\hline ELP workshops & 2.86 & 3.43 & 4.33 & 3.50 \\
ELP tutoring & 3.00 & 4.00 & 4.83 & 3.90 \\
ELP conversation hours & 2.43 & 3.29 & 4.17 & 3.25 \\
Tutoring from PACE & 4.00 & 3.43 & 3.16 & 3.55 \\
Workshops from PACE & 3.71 & 3.43 & 3.50 & 3.50 \\
Workshops from library & 3.29 & 3.29 & 3.33 & 3.30 \\
Workshops from health services & 3.71 & 3.71 & 3.83 & 3.75 \\
Advising from professors & 4.00 & 3.86 & 3.33 & 3.75 \\
\hline
\end{tabular}

Note. ELP = English Language Program; PACE = Programs for Academic Access, Confidence and Excellence. Scale: 1 (not at all helpful), 2 (a little helpful), 3 (helpful), 4 (very helpful), or 5 (extremely helpful).

Throughout the three semesters, participants generally found all of the services helpful to very helpful. In the fall term, participants highly appreciated tutoring from Programs for Academic Access, Confidence, and Excellence (PACE), workshops from PACE, workshops from Health Services, and advice from professors. In their last semester, although some services were no longer offered by the ELP to the participants in that semester, participants found English Language Program (ELP) workshops, ELP tutoring, and ELP conversation hours very and extremely helpful.

When asked about the usefulness of services provided in the three interviews, participants mentioned the usefulness of a conversation group from a Chinese church they went to, conversation hours offered by the ELP, conversation partners they were paired with by the ELP, activities at the university that they participated in, and even the three interviews with the second researcher. While participants clearly appreciated these opportunities to talk and connect with other people, they recommended more for future students. They also asked for more everyday English or "life words" and more "supporting of life" from the university. Overall, participants left the last interview with positive feelings of success and personal growth. Based on the participants, the researchers confirmed their success in completing the program and advancing their career back in China. Talking about the whole experience, one participant stated:

This year was exciting. I learned a lot from this year. Actually not only from my nursing area, but also to live in a different culture, eat different food. Also I traveled a lot in the US, and I have been to many places, the West, the East. I learned a lot from travel: different transportation, different culture, different language. I think it has been an unforgettable experience. I will always remember this year-all that I have experienced.

Others also used such words as perfect, unforgettable, and comfortable to describe their experiences. 


\section{Summary of Findings}

In summary, the main findings from both the quantitative and qualitative analyses identified a general decline in challenges over the three semesters, but writing and listening remained difficult to most participants. The difficulties stemmed from the linguistic demands of the writing and listening tasks and the participants' unfamiliarity with the academic writing style. Reading was found the least challenging because of their prior exposure to reading and the time they could spend reading independently using various resources. Perceptions of speaking were mixed since speaking tasks and situations varied. Interestingly, speaking was a source of quite a few mixed emotions: anxiety, shame, embarrassment, and also pride, satisfaction, and joy. Participants reported frequent use of different strategies and mentioned conscious efforts to improve their language skills and succeed in their graduate course work. However, the use of specific strategies varied from semester to semester based on the demands of the courses taken at the time. In addition, there was increased use of social strategies as participants continued to seek support from peers, tutors, and professors. Finally, participants found the support services, especially tutoring services and programs that offered opportunities for social interactions, helpful, but recommended more speaking opportunities and "life support" for future students.

\section{Discussion}

Consistent with previous research (Kuo, 2011; Leong, 2015; Mitchell et al., 2017; Wang et al., 2015), this study suggests that challenges confronting international students studying abroad in their second language are multifaceted. They occur both inside and outside the classroom. The finding regarding the difficulty with academic writing was not a surprise considering the high linguistic demands of graduate-level writing tasks and the lack of preparation in academic writing among international students despite having an acceptable standardized test language score (Kuo, 2011). This finding highlights the importance of providing formalized writing instruction and support to international students who are still acquiring a new language, learning to write academically, and only starting to socialize into their disciplinary discourse. Apart from the support from an ESL program, faculty teaching content courses could make academic content comprehensible through sheltered instruction techniques, which are commonly used in the K-12 setting in the mainstream classes including English language learners (Echevarria, Vogt, \& Short, 2016; He \& Hutson, 2018). Taking challenges faced by international students into consideration, they could also present their expectations and grading rubrics more explicitly to international students. In addition, the difficulty with listening may be due to the demands of processing new content in real time and the participants' unfamiliarity with listening to and using English beyond doing exercises presented in textbooks, a common scenario in countries like China, where teaching and assessment focus mostly on vocabulary, grammar, and reading (Nunan, 2003). This difficulty needs to be taken into account by those instructing and interacting with international students.

Regarding oral communication, similar to previous research, difficulties with oral communication affected participants' sense of confidence and self-esteem and resulted in negative emotions and even stress (Kuo, 2011; Li et al., 2018; Mitchell et al., 2017). These 
negative emotions may lead to a decreased sense of social satisfaction and belonging, and overall student engagement (Horne et al., 2018). On the other hand, communicative success in academic and everyday situations promoted a sense of competence and induced positive emotions of pride, satisfaction, and joy. In language learning, the enjoyment derived from successfully communicating with others itself has been linked to higher engagement in learning activities and motivation to seek similar activities, which are important factors in L2 success (Egbert, 2003; Phung, 2017). This finding suggests institutions enrolling international students need to organize opportunities that allow the students to interact with others in a supportive environment where interlocutors are willing to negotiate meaning to achieve mutual understanding and communicative success. This means faculty, staff, and local students should, among other things, consider slowing down when lecturing and speaking and be patient and allow international students more time to formulate their thoughts before speaking.

Regarding strategy use, the study suggested that graduate nursing students in this cohort were active learners as reflected in the frequent use of metacognitive strategies (or learning strategies) and cognitive strategies noted in the survey results and interviews. These findings indicated participants' intentional and intense effort in managing their language development and academic coursework. In addition, individual learning efforts were balanced with one's utilization of social strategies as they frequently sought support from peers, tutors, and professors. Together with the usefulness of support services offered at the university, this level of strategy use may explain the decline in the challenges they faced, the progress participants reported during the last interview, and the overall positive experience with their program. The study suggests that, even with numerous challenges and less than advanced English proficiency level, appropriate accommodations and services as well as student efforts can result in student success and satisfaction in graduate studies abroad. In addition, the support from peers reported in the study suggests that studying abroad in a cohort has its own advantages because students have access to a supportive network of peers in their studies and in their daily life. This finding is consistent with Jessup-Anger and Aragones (2013), who identified that students of the same cohort interacted frequently for companionship and learning needs, which positively influenced their overall experiences. Contrary to the argument that international students need to be integrated with local students to benefit from their study abroad, cohort-based programs like the one in this study may work well especially when international students will return to work in their home country.

\section{Conclusion}

Nursing programs in the US and Australia have been attracting international students, including Chinese nurses to obtain a higher nursing degree outside of their home country. As universities prepare to accept international students, they must understand students' challenges, coping strategies, and experiences and provide services that will help them succeed. The findings from this study suggest that international students face numerous challenges, but can also be quite active in their learning through flexible strategy use. ESL and academic support services provided by the university; considerations by faculty; the kindness and patience of professors, staff, and local students; and a supportive peer 
network are likely important in promoting international students' positive experience and success. In addition, studying abroad in a cohort versus integrating into existing programs presents its own advantage as a model of international education.

The researchers would like to acknowledge some limitations of the study, including a small sample size and the variation in the quantitative data, which limit the generalizability of the findings to other contexts. Despite the limitations, the study offers insights that may be useful for higher education institutions in supporting international student success in general and developing programs to international nursing students from China in particular.

\section{References}

Dornyei, Z. (2010). The psychology of the language learner: Individual differences in Second Language Acquisition. Routledge, New York, NY.

Echevarria, J., Vogt, M. E., \& Short, D. J. (2016). Making content comprehensible for English learners: The SIOP Model. Pearson, Boston, MA.

Egbert, J. (2003). A study of flow theory in the foreign language classroom. The Modern Language Journal, 87(4), 499-518.

Green, J. M. \& Oxford, R. L. (1995). A closer look at learning strategies, L2 proficiency, and gender. TESOL Quarterly, 29(2), 261-297.

Griffiths, C. (2003). Patterns of language learning strategy use. System, 31, 367-383.

Griffiths, C. \& Oxford, R. L. (2014). The twenty-first century landscape of language learning strategies: Introduction to this special issue. System, 43, 1-10.

$\mathrm{Gu}, \mathrm{Q}$. (2011). An emotional journal of change: The case of Chinese students in UK higher education. In Jin, L. \& Cortazzi, M., editors, Researching Chinese learners, pages 212-232, New York, NY. Palgrave Macmillan.

He, Y. \& Hutson, B. (2018). Exploring and leveraging Chinese international students' strengths for success. Journal of International Students, 8(1), 87-108.

Horne, S., Lin, S., Anson, M., \& Jacobson, W. (2018). Engagement, satisfaction, and belonging of international undergraduates at U.S. research universities. Journal of International Students, 8(1), 351-374.

Huang, Y. (2012). Transitioning challenges faced by Chinese graduate students. Adult Learning, 23(3), 138-147.

J., J.-A. \& Aragones, A. (2013). Students' peer interactions within a cohort and in host countries during a short-term study abroad. Journal of Student Affairs Research and Practice, 50(1), 21-36.

Kuo, Y. (2011). Language challenges faced by international graduate students in the United States. Journal of International Students, 1(2), 38-42.

Lee, J. J. (2010). International students' experiences and attitudes at a US host institution: Self-reports and future recommendations. Journal of Research in International Education, 9, 66-84.

Leong, P. (2015). Coming to America: Assessing patterns of acculturation, friendship formation, and the academic experiences of international students at a U.S. college. Journal of International Students, 5(4), 459-474. 
Li, J., Wang, Y., X., L., Xu, Y., \& T, C. (2018). Academic adaptation among international students from East Asian countries: A consensual qualitative research. Journal of International Students, 8(1), 194-214.

Mitchell, C., Fabbro, L. D., \& Shaw, J. (2017). The acculturation, language and learning experiences of international nursing students: Implications for nursing education. Nurse Education Today.

Nunan, D. (2003). The impact of English as a global language on educational policies and practices in Asia-Pacific region. TESOL Quarterly, 37(4), 589-613.

Oxford, R. L. (1990). Language learning strategies: What every teacher should know. House, New York, NY: Newbury.

Oxford, R. L. \& Burry, J. A. (1993). Evolution, norming, and psychometric testing of Oxford's Strategy Inventory for Language Learning. Paper presented at the annual meeting of the National Council on Measurement in Education, Atlanta, GA.

Oxford, R. L. \& Burry-Stock, J. A. (1995). Assessing the use of language learning strategies worldwide with the ESL/EFL version of the Strategy Inventory for Language Learning. (SILL). System, 23, 153-175.

Ozgur, B. \& Griffiths, C. (2013). Second language motivation. Procedia -. Social and Behavioral Sciences, 70, 1109-1114.

Parris-Kidd, H. \& Barnett, J. (2011). Cultures of learning and student participation: Chinese learners in a multicultural English class in Australia. In Jin, L. \& Cortazzi, M., editors, Researching Chinese learners, pages 169-187, New York, NY. Palgrave Macmillan.

Phung, L. (2017). Task preference, affective response, and engagement in L2 use in a US university context. Language Teaching Research, 21(6), 751-766.

Rosenthal, D. A., Russell, J., \& Thomson, G. D. (2008). The health and wellbeing of international students at an Australian university. Higher Education, 55, 51-67.

Wang, C., Andre, K., \& Greenwood, K. (2015). Chinese students studying at Australian universities with specific reference to nursing students: A narrative literature review. Nurse Education Today, 35, 609-619.

\section{Author biography}

Debra M Wolf is a Professor of Nursing in the School of Health Sciences at Chatham University. Her major research interests lie in the area of academic literacies, international study abroad, healthcare informatics.

Linh Phung is the Director, English Language and Pathways Programs within the Office of International Affairs at Chatham University. Her major research interests lie in the areas of Second Language Acquisition, task-based language teaching, and international education. 